\title{
Exploration of experiences in therapeutic groups for patients with severe mental illness: development of the Ferrara group experiences scale (FE- GES)
}

Rosangela Caruso ${ }^{1}$, Luigi Grassi ${ }^{1,2}$, Bruno Biancosino ${ }^{2 *}$, Luciana Marmai ${ }^{2}$, Luciano Bonatti ${ }^{3}$, Maria Moscara ${ }^{4}$, Marco Rigatelli ${ }^{4}$, Catherine Carr ${ }^{5}$ and Stefan Priebe ${ }^{5}$

\begin{abstract}
Background: Group therapies are routinely provided for patients with severe mental illness. The factors important to the group experience of patients are still poorly understood and are rarely measured. To support further research and practice, we aimed to develop a questionnaire that captures how patients experience groups within a community mental health context.

Methods: An initial pool of 39 items was conceptually generated to assess different aspects of group experiences. Items were completed by 166 patients with severe mental illness attending group therapies in community mental health services in Italy. Patients with different psychiatric diagnoses who attended at least 5 group sessions were included. An exploratory factor analysis was used to identify different dimensions of group experiences and to reduce the number of items for each dimension.

Results: The resulting questionnaire has five subscales: 1) sharing of emotions and experiences, 2) cognitive improvement, 3) group learning, 4) difficulties in open expression and 5) relationships. Each subscale has 4 items. The scale and sub-scales have good internal consistency.

Conclusions: The Ferrara Group Experiences Scale is conceptually derived and assesses dimensions of group experience that are theoretically and practically relevant. It is brief, easy to use and has good psychometric properties. After further validation, the scale may be used for research into patient experiences across different group therapy modalities and for evaluation in routine care.
\end{abstract}

Keywords: Group therapy, Patient experiences, Severe mental illness, Community mental health care

\section{Background}

Since the introduction of therapeutic communities in the 1940s, group treatments have become a common part of care for patients with severe mental illness [1-7]. Group treatments are widely provided in psychiatric settings and generally considered as a routine therapeutic intervention [8-11]. It has been suggested that group experiences can be a powerful agent of change and efficacy has been demonstrated across a range of approaches

\footnotetext{
* Correspondence: b.biancosino@ausl.fe.it

${ }^{2}$ Department of Mental Health and Drug Abuse, Ferrara Health Agency, Ferrara, Italy

Full list of author information is available at the end of the article
}

including cognitive-behavioural therapy [8], integrated psychological therapy [9], social skills training [10], cognitive remediation [11], and others [12-17].

Several processes have been proposed to explain the mechanisms of group therapy $[1,4,5,18,19]$. Yalom's studies of the essential mechanisms for change common to group treatments [20,21] identified eleven factors consisting of: 1) instillation of hope, 2) universality, 3) imparting of information, 4) altruism, 5) the corrective recapitulation of the primary family group, 6) development of socializing techniques, 7) imitative behaviour, 8) interpersonal learning, 9) group cohesiveness, 10) catharsis, and 11) existential factors. Bloch and Crouch [22] later formulated a 
model that proposed self-disclosure and self-understanding as predictors of change. A recent study suggests that Yalom's factors do not have equal importance to patients and therapists. Cohesiveness, universality and self-understanding were indicated as most important in the group experience [23].

A number of scales have been developed to explore different aspects of group treatment. Many have been designed to specifically evaluate the presence of Yalom's 11 factors [6,7,23-27]. More recently, Dierick and Lietaer [28], developed a questionnaire to investigate therapeutic factors across an extensive range of group therapies from the client's perspective. Participants were diverse and represented inpatients and outpatients, as well as students and trainee psychotherapists. Therapeutic approaches included client centred/experiential, Gestalt, psychoanalytic, behavioural, drama and body therapies. The questionnaire comprised of 133 items and 28 basic scales. Questions were written from the perspective of the patient's experience, and focused primarily on helpful or instructive experiences. The method used a series of multivariate analyses to define the links between therapeutic factors and their degree of interconnectedness. Two different dimensions were proposed to account for the therapeutic factors intervening in groups. These two dimensions were interpreted as "Relational Climate" and "Psychological Work".

Despite the comprehensiveness of this questionnaire, its use may be limited in a community mental health setting as the number of items makes the scale difficult to implement in routine clinical evaluation and items were derived from a mostly non-clinical sample. The questionnaire focuses only on items experienced as helpful or instructive and therefore does not explore experiences and feelings that were perceived as less therapeutic or detrimental.

Despite the body of research regarding therapeutic mechanisms in group treatment, a valid, brief and robust scale that explores the core experiences of patients (therapeutic or not) during a single session or course of group therapy does not currently exist in community psychiatry. The purpose of this study was to develop and perform a primary validation of a questionnaire to assess the main subjective experiences of patients with severe mental illness attending group therapy. The questionnaire was designed to be specific to community mental health services, short and easy to administer and to capture different but theoretically meaningful dimensions of experiences across a range of group interventions and community settings.

\section{Methods}

\section{Setting}

The study took place in community mental health services of three provinces in North-east Italy. Settings included a residential unit in Ferrara, providing short-to medium-term care for patients with acute and subacute psychiatric conditions, and two psychiatric day-hospitals in Bologna and Modena. A range of group activities are regularly offered within these settings and patients are invited and encouraged to participate in all groups.

\section{Group intervention}

Group interventions were scheduled on weekly basis. All groups lasted for 90 minutes, except the psychodynamic group (60 minutes) and had the following characteristics:

- Group psychodynamic psychotherapy provided opportunities for each member to learn about themselves and their interpersonal and intra-psychic functioning, by creating a safe atmosphere that encouraged interaction and invited reflection.

- Psychosocial rehabilitation groups (e.g. newspaper reading groups) had a more practical focus, whilst pursuing the improvement of patients' cognitive and social skills.

- Psycho-educational groups (such as a "wellness group") provided patients with information about their psychiatric disorders, pharmacological treatments and healthy living.

- Expressive groups (such as arts and music therapy groups) gave patients the opportunity to be creative and encouraged self-expression.

- Body oriented groups included a relaxation group and psycho-motor group.

- "Other" groups represented groups where patients could discuss issues and raise concerns.

\section{Generation of the item pool}

The questionnaire was developed in several steps. At each stage, decisions were discussed and made by the project team in Italy and then further checked with an expert in scale development (SP) to reduce bias.

An initial item pool was generated by focus groups held in three community mental health services between September-October 2009 (Ferrara, coordinating centre; Modena and Bologna). Each group comprised of clinicians from different professional backgrounds that commonly participate in the management of groups (Ferrara: 2 psychiatrists, 5 psychiatric nurses, 2 social workers, 1 psychologist; Modena: 2 psychiatrists, 2 psychiatric nurses, 2 rehabilitation therapists, 1 psychologist; Bologna: 1 psychiatrist, 5 psychiatric nurses, 2 rehabilitation therapists and 1 psychologist). Each focus group met four times. The task of each meeting was to generate a complete list of common therapeutic group experiences which resulted in a list of 25 group experiences from the Ferrara group, 21 from Modena and 26 from Bologna. 
The items were then examined by the coordinating centre in Ferrara and grouped into common dimensions. Four conceptual dimensions resulted: relational aspects, expression of emotions and mentalization, group learning, and cognitive experiences. Four statements that most clearly represented each dimension were selected from the lists, to form a total of 16 experiences.

These were then transformed into specific questions with multiple questions for each statement to ensure comprehensive coverage (7 questions for relational aspects, 6 for expressions of emotions and mentalization, 6 for group learning, and 6 for cognitive improvement). This resulted in a pool of 25 questions which was circulated and approved by all the participating centres. Inverse items were then included ( 3 for relational aspects, 3 for expression of emotions, 4 for group learning and 3 for cognitive improvement) expanding the pool to 38 questions.

The questionnaire was read in a meeting with 12 psychiatric patients (5 with a diagnosis of schizophrenia, 3 with bipolar disorder, 3 with unipolar depression and 1 with borderline personality disorder) to verify that all items were clearly understandable and made sense. Any words that were unclear were exchanged with words suggested by the group. On the final reading, all questions were deemed understandable by the patients.

The resulting self-report instrument (Ferrara Group experiences Scale - FE-GES) assessed the main subjective experiences of participants in group therapy and the intensity this was felt. It consisted of 38 items evaluating the four hypothesised areas of relationships (e.g. "I was helped by others", "I socialised with others"), emotional expression and mentalization (e.g. "I shared my personal experiences and my life problems", "I met people who were experiencing the same problems as me"), group learning (e.g. "I understood the reasons for my behaviour", "I understood better how I usually deal with my problems") and cognitive improvement (e.g. "I paid attention to what others said", "I could remember what was said").

Items were rated on a 5-point Likert scale, from not at all (0), a little (1), enough (2), very (3) to a great deal (4). Items $3,7,11,13,16,18,22,24,26,28,32,34$ and 38 were inversely scored.

A further item was included, which asked the participant to rate the overall usefulness of the group. The questionnaire was written in Italian.

\section{Data collection}

Psychiatric patients admitted to the participating services between January 1, 2010 and April 30, 2011 were screened for inclusion. Eligible patients were those with any psychiatric diagnosis according to ICD-10 criteria except for mental retardation (ICD-10 codes F70 to F79), who chose to take part in at least 5 group activity sessions of any modality and consented to participate in the study. Patients completed a psychiatric diagnostic interview according to ICD-10 criteria on admission. All patients were informed of the aim of the study and gave written informed consent. The study was conducted in line with the Code of Ethics of the World Medical Association (Declaration of Helsinki, 1964) and approved by the institutional review board of the University of Ferrara. Socio-demographic and clinical data (e.g. length of illness and number of hospitalizations) were collected. Prior to discharge from services, patients were asked to complete the questionnaire to rate their overall group experiences during the period of admission.

\section{Statistical analysis}

Principle Components Analysis (PCA) of the 39 items was used to identify any underlying dimensions of this questionnaire. Both orthogonal (varimax) and oblique (directoblimin) rotations were examined using the FACTOR program [29]. Descriptive statistics were used to check the distribution of the data and to identify items with high values of skewness or kurtosis. Polychoric correlations were employed to account for the Likert scale response [30]. Inter-correlations between items were examined for particularly high or low correlations and the KaiserMeyer-Olkin measure was used to verify sampling adequacy. The strength of relationships between variables was assessed using Bartlett's test of sphericity. The number of components to retain was first estimated by parallel analysis [31]. Rotations were examined for a range of 2-6 specified components around this estimate, and a criterion level of 0.4 was set to determine the importance of factor loadings [32]. Reliability of the rotated factor scores [33,34], Bentler's [35] simplicity and Lorenzo-Seva's [36] loading simplicity indices were then examined. Pattern and structure matrices were inspected in oblique rotations for items loading highly onto more than one component and the correlation matrix analysed to determine whether there were relationships between components. Low correlating and highly skewed items were systematically removed and the analysis re-run. The final solution was selected based upon criteria of explanation of a good proportion of the variance, balance of loading onto components and conceptual similarity. Items with the highest loadings onto components were selected and analysed for internal consistency using Cronbach's $\alpha$ in PASW Statistics (v.18). A criteria of $\alpha>.7$ was set as a minimum [37].

\section{Results}

Sociodemographic and clinical characteristics of patients During the study period, 191 patients were admitted across the 3 participating centres, of which 166 were 
eligible and consented to participate. Table 1 displays rates of participation in each group.

The sample consisted of 58 men (35\%) and 108 women $(65 \%)$, with a mean age of $46.4( \pm 12.2)$ years. Half of the participants had never married (83; 50\%); 44 were married (27\%), 31 divorced (19\%) and 8 widowed (5\%). Most were unemployed (120; 72\%), while 46 had a job (28\%). Most of the participants had spent 8 years or more in education (153; 92\%).

According to ICD-10 criteria, 57 patients were diagnosed with schizophrenia (34\%), 4 with delusional disorder (2\%); 10 with schizoaffective disorder (6\%), 29 with bipolar disorder (18\%), 27 with major depressive disorder (16\%), 26 with personality disorder (16\%), 12 with eating disorder (7\%), and one with an anxiety disorder (1\%). Mean age at illness onset was 29.6 ( \pm 13.1) years. The mean number of previous hospitalizations was $6.4( \pm 7.7)$.

\section{Principal components analysis}

Item responses used the full range of scores (0-4) for each item, but many were highly skewed indicating that polychoric correlation coefficients were required [30,37-39]. The Kaiser-Meyer-Olkin measure verified the sampling adequacy for the analysis, $\mathrm{KMO}=0.744$. Nine items had correlations lower than .3, but none had high correlations $(>.8)$. Diagonals of the anti-image correlation matrix were all above .5 . Bartlett's test of sphericity $\left(\chi^{2}(166)=\right.$ 3024.3, $p<.001)$, indicated that relations between items were sufficiently large for PCA.

Parallel analysis using 500 random correlation matrices permuted from the raw data [40] suggested three components should be retained (Table 2). After rotation, the items appeared to split into positively and negatively phrased (inversely scored) components. Cognitive improvement, plus an additional group learning item (item 23) appeared as a consistent component in all 3-6 component solutions. Of these, the 5-component solution was most promising as it explained $50.5 \%$ of the variance and had a better conceptual fit. Removal of low correlating items did not significantly improve the explained variance of the model whilst removal of seven inversely scored, highly skewed items resulted in a 5 component solution which explained $50.8 \%$ of the variance. This solution was selected as it provided better conceptual distinction between the previously defined components of sharing of emotions and experiences, cognitive improvement, group learning, difficulties in open expression and relationships.

Four items loaded highly (>.5) onto each component. PCA of these 20 items explained $60.8 \%$ of the variance. Orthogonal and oblique rotations were similar. As components were moderately correlated, the oblique rotation was preferred (Tables 3 and 4). Reliability analysis using Cronbach's $\alpha$ on standardised values [37] demonstrated good reliability for all sub-scales and item totals (Table 5).

\section{Discussion}

Group interventions are widely provided in psychiatric settings, yet there is a paucity of research that focuses upon patients' experiences of group sessions. In this study, a scale was developed that assessed group experiences of 166 patients with severe mental illness from three Italian community mental health centres. The Ferrara Group Experiences Scale (FE-GES) is relatively brief tool, consisting of 5 subscales with a total of 20 items which capture important and distinct aspects of patient experiences. It resulted from a systematic and conceptually driven development, and shows good psychometric qualities.

The five subscale components confirm factors identified in previous research and identify new aspects that invite further reflection. Below, the five subscale factors are described and their relationship to existing literature is briefly discussed.

Table 1 Number of patients participating in groups by diagnosis

\begin{tabular}{|c|c|c|c|c|c|c|c|}
\hline \multicolumn{2}{|c|}{$\begin{array}{l}\text { Diagnosis (number of patients with } \\
\text { that diagnosis and percentage in } \\
\text { relation to the total) }\end{array}$} & \multirow{2}{*}{$\begin{array}{l}\begin{array}{l}\text { Psychodynamic } \\
\text { therapy }\end{array} \\
44(77 \%)\end{array}$} & \multirow{2}{*}{$\begin{array}{l}\begin{array}{l}\text { Psychosocial } \\
\text { rehabilitation } \\
\text { group }\end{array} \\
92(56 \%) \\
\end{array}$} & \multirow{2}{*}{$\begin{array}{l}\begin{array}{l}\text { Psycho- } \\
\text { educational } \\
\text { group }\end{array} \\
16(28 \%)\end{array}$} & \multirow{2}{*}{$\begin{array}{l}\begin{array}{l}\text { Expressive } \\
\text { group }\end{array} \\
40(70 \%)\end{array}$} & \multirow{2}{*}{\begin{tabular}{|l|}
$\begin{array}{l}\text { Bodily } \\
\text { mediated } \\
\text { group }\end{array}$ \\
$29(51 \%)$ \\
\end{tabular}} & \multirow{2}{*}{$\begin{array}{l}\text { Others } \\
11(19 \%)\end{array}$} \\
\hline Schizophrenia & $57(34 \%)$ & & & & & & \\
\hline Delusional Disorder & $4(2 \%)$ & $3(75 \%)$ & $1(25 \%)$ & $1(23 \%)$ & $2(50 \%)$ & $1(25 \%)$ & $0(0 \%)$ \\
\hline Schizo-affective Disorder & $10(6 \%)$ & $8(80 \%)$ & 7 (70\%) & $3(30 \%)$ & 7 (70\%) & $4(40 \%)$ & $4(40 \%)$ \\
\hline Bipolar Disorder & $29(18 \%)$ & $26(90 \%)$ & $12(41 \%)$ & $8(28 \%)$ & $12(41 \%)$ & $12(41 \%)$ & $5(17 \%)$ \\
\hline Major Depression & $27(16 \%)$ & $26(96 \%)$ & $13(48 \%)$ & $10(37 \%)$ & $13(48 \%)$ & $12(44 \%)$ & $5(9 \%)$ \\
\hline Anxiety Disorder & $1(1 \%)$ & $1(100 \%)$ & $0(0 \%)$ & $0(0 \%)$ & $0(0 \%)$ & $0(0 \%)$ & $0(0 \%)$ \\
\hline Eating Disorder & $12(7 \%)$ & $11(92 \%)$ & $1(8 \%)$ & $1(8 \%)$ & $0(0 \%)$ & $1(8 \%)$ & $2(17 \%)$ \\
\hline Personality Disorder & $26(16 \%)$ & $25(96 \%)$ & $15(58 \%)$ & $8(31 \%)$ & $15(58 \%)$ & $11(42 \%)$ & $3(12 \%)$ \\
\hline Total & $166(100 \%)$ & $144(87 \%)$ & $81(49 \%)$ & $47(28 \%)$ & $89(54 \%)$ & $70(42 \%)$ & $30(18 \%)$ \\
\hline
\end{tabular}


Table 2 Parallel analysis results: eigenvalues greater than 1 and proportions of variance explained $(N=166)$

\begin{tabular}{|c|c|c|c|c|c|}
\hline Variable & Eigenvalue & $\begin{array}{l}\text { Mean of random } \\
\text { eigenvalues }\end{array}$ & $\begin{array}{l}95 \text { percentile of } \\
\text { random eigenvalues }\end{array}$ & $\begin{array}{l}\text { Proportion of } \\
\text { variance }\end{array}$ & $\begin{array}{l}\text { Cumulative } \\
\text { proportion } \\
\text { of variance }\end{array}$ \\
\hline 1 & 8.858 & 2.585 & 2.750 & .227 & .227 \\
\hline 2 & 5.569 & 1.858 & 1.963 & .143 & .370 \\
\hline 3 & 2.071 & 1.744 & 1.823 & .053 & .423 \\
\hline 4 & 1.637 & 1.657 & 1.724 & .042 & .465 \\
\hline 5 & 1.557 & 1.585 & 1.641 & .040 & .505 \\
\hline 6 & 1.300 & 1.523 & 1.584 & .033 & .538 \\
\hline 7 & 1.231 & 1.461 & 1.516 & .032 & .570 \\
\hline 8 & 1.117 & 1.407 & 1.452 & .029 & .599 \\
\hline
\end{tabular}

Suggested number of variables to retain highlighted in bold.

\section{Sharing of emotions and experience}

The experience of "sharing" with the therapist and other group members is regarded as one of the core elements to promote change in group treatments. In this subscale several existing factors are reflected: 1 ) sense of universality, 2) development of socializing abilities, 3) self understanding and 4) imitative behaviour [19]. As mentioned previously, universality, self-understanding, and cohesiveness have recently been indicated as the most important therapeutic factors [23]. Sharing of emotions and experiences among group members appears to be the core element of self-disclosure, suggested by Bloch and Crouch [22] as a driver of change. Sharing emotions and experiences may also contribute to the quality of the relational climate that Dierick and Lietaer described as a fundamental dimension of group therapies [28,41-43].

\section{Cognitive improvement}

This subscale corresponds to Yalom's concept of "imparting of information" [6,7]. It captures how cognitive abilities can be elicited and strengthened within the group process. Participants can improve their ability to focus, to remember what was said, to express thoughts in a clear way, and to listen. The items suggest that this improvement is connected to the relational aspect of listening and paying attention to statements of other patients, an intrinsic characteristic of group treatments.

\section{Group learning}

The "Group learning" factor corresponds to research on group learning processes and reflects Yalom's concepts of interpersonal learning and self understanding [6,7]. These concepts refer to developing a greater capacity to understand the rules and codes of relationships, achieving a higher level of self-awareness (self-understanding) and insight into the origins of problems and the unconscious motivations that underlie behaviours ("genetic insight") [7]. Similar concepts are found in the work of MacKenzie [44] and Dierick and Lietaer [28], who by rearranging Yalom's therapeutic factors, indicated the elements of "interpersonal learning" and "self-understanding" as an underlying dimension of psychological work.

\section{Difficulties in open expression}

The conceptual development of the FE-GES has identified an aspect of group participation which, so far, has not been considered in group experience scales. The items of this subscale contrast with the therapeutic experiences described so far, indicating patients' discomfort in talking about problems and communicating opinions and feelings. These obstacles to self- expression during group sessions may originate from therapists' failure to build a safe and non-judgemental atmosphere, from the existence of strong cultural or social diversities within the group, or from the subjective characteristics of one or more members. In their study of inpatient psychotherapy groups, Leszcz, Yalom and Norden [24] suggested that the heterogeneous needs and capacities of patients may require a range of differing forms and structures in groups. When these difficulties arise, it is crucial that the therapist is aware of them so that these problems can be addressed. Such difficulties may undermine participation within the group and the success of intervention, by hampering the development of cohesion and self-disclosure [22]. This subscale may provide a means of identifying such difficulties during the therapy process and enable clinicians to adjust therapeutic programs to meet individual needs. It is important to note that these 'negative' experiences do not imply the absence of positive experiences, which would be captured by low scores on the other subscales. It is a distinct factor which may assist in improving group experiences of psychiatric patients.

\section{Relationships}

This subscale has strong links to many of the proposed therapeutic factors in group psychotherapy research. Several of Yalom's therapeutic factors are reflected: 
Table 3 Oblique rotation of 5 components with final 20 items and item reliability

\begin{tabular}{|c|c|c|c|c|c|c|c|c|c|c|c|}
\hline \multirow[b]{2}{*}{ Item } & \multirow[b]{2}{*}{ Area } & \multicolumn{2}{|c|}{$\begin{array}{l}\text { Component 1: } \\
\text { cognitive } \\
\text { improvement }\end{array}$} & \multicolumn{2}{|c|}{$\begin{array}{l}\text { Component 2: } \\
\text { group learning }\end{array}$} & \multicolumn{2}{|c|}{$\begin{array}{l}\text { Component 3: } \\
\text { relationships }\end{array}$} & \multicolumn{2}{|c|}{$\begin{array}{l}\text { Component 4: } \\
\text { difficulties in } \\
\text { open expression }\end{array}$} & \multicolumn{2}{|c|}{$\begin{array}{l}\text { Component 5: } \\
\text { sharing of } \\
\text { emotions and } \\
\text { experiences }\end{array}$} \\
\hline & & Pattern & Structure & Pattern & Structure & Pattern & Structure & Pattern & Structure & Pattern & Structure \\
\hline $\begin{array}{l}\text { 36. I listened to others carefully in } \\
\text { the group }\end{array}$ & $\mathrm{Cl}$ & .898 & .905 & .053 & .254 & .017 & .163 & -.021 & .223 & -.038 & .028 \\
\hline $\begin{array}{l}\text { 30. I paid attention to what others } \\
\text { said in the group }\end{array}$ & $\mathrm{Cl}$ & .872 & .859 & -.161 & .067 & .071 & .175 & .042 & .266 & .015 & .053 \\
\hline $\begin{array}{l}\text { 35. I expressed my thoughts clearly } \\
\text { in the group }\end{array}$ & $\mathrm{Cl}$ & .505 & .547 & .288 & .374 & -.313 & -.096 & .040 & .186 & .253 & .278 \\
\hline $\begin{array}{l}\text { 33. I could remember what was } \\
\text { said in the group }\end{array}$ & $\mathrm{Cl}$ & .462 & .527 & .267 & .384 & -.145 & .054 & .049 & .203 & .224 & .278 \\
\hline $\begin{array}{l}\text { 29. In the group, I realised how } \\
\text { much my behavioural problems } \\
\text { have improved }\end{array}$ & $\mathrm{GL}$ & -.205 & -.011 & .727 & .717 & .056 & .244 & .052 & .099 & .076 & .225 \\
\hline $\begin{array}{l}\text { 19. I understood the reasons for } \\
\text { my behaviour in the group }\end{array}$ & EE & .016 & .190 & .665 & .712 & .095 & .295 & .003 & .107 & .086 & .239 \\
\hline $\begin{array}{l}\text { 21. In the group, I understood better } \\
\text { how I usually deal with my problems }\end{array}$ & $\mathrm{GL}$ & .093 & .257 & .605 & .679 & .155 & .344 & -.010 & .114 & .057 & .214 \\
\hline $\begin{array}{l}\text { 23. I learned how to manage good } \\
\text { ineractinos with others in the group }\end{array}$ & $\mathrm{GL}$ & .235 & .352 & .578 & .571 & .127 & .220 & -.032 & .074 & -.463 & -.310 \\
\hline $\begin{array}{l}9.1 \text { met new and positive people } \\
\text { in the group }\end{array}$ & $R$ & -.034 & .091 & .045 & .246 & .759 & .769 & -.027 & .084 & .036 & .198 \\
\hline $\begin{array}{l}8.1 \text { built relationships of trust with } \\
\text { others in the group }\end{array}$ & $R$ & .065 & .220 & .124 & .348 & .696 & .763 & .044 & .185 & .078 & .256 \\
\hline $\begin{array}{l}\text { 5. I was helped by others in the } \\
\text { group. }\end{array}$ & $R$ & -.087 & .027 & .109 & .298 & .557 & .632 & -.070 & .033 & .334 & .460 \\
\hline 6. I socialised with others in the group & $\mathrm{R}$ & .306 & .465 & .048 & .268 & .520 & .597 & .272 & .424 & -.119 & .042 \\
\hline *18. I hid my feelings in the group & $\mathrm{EE}$ & .011 & .217 & -.199 & -.059 & .104 & .187 & .877 & .875 & .028 & .094 \\
\hline $\begin{array}{l}\text { *38. I found it difficult to express } \\
\text { my thoughts clearly in the group }\end{array}$ & $\mathrm{Cl}$ & .005 & .258 & .098 & .195 & .010 & .156 & .871 & .881 & -.047 & .057 \\
\hline $\begin{array}{l}\text { *16. I was afraid to express my } \\
\text { opinion in the group }\end{array}$ & $\mathrm{EE}$ & .083 & .294 & -.057 & .061 & -.025 & .103 & .853 & .867 & .025 & .094 \\
\hline $\begin{array}{l}\text { *13. It was hard for me to talk } \\
\text { about my problems in the group }\end{array}$ & $\mathrm{EE}$ & -.123 & .122 & .186 & .225 & -.101 & .048 & .824 & .798 & -.012 & .075 \\
\hline $\begin{array}{l}\text { 2. I met people in the group who } \\
\text { were experiencing the same } \\
\text { problems as me }\end{array}$ & R & -.042 & -.011 & -.013 & .126 & .061 & .189 & -.065 & -.002 & .705 & .706 \\
\hline $\begin{array}{l}\text { 1. Within the group I shared my } \\
\text { personal experiences and life } \\
\text { problems. }\end{array}$ & R & .193 & .319 & .124 & .330 & .077 & .293 & .186 & .320 & .599 & .669 \\
\hline $\begin{array}{l}17 . \text { I talked with others about my } \\
\text { suffering in the group }\end{array}$ & $\mathrm{EE}$ & .067 & .144 & .066 & .253 & .220 & .365 & -.028 & .084 & .579 & .639 \\
\hline $\begin{array}{l}\text { 12. I was able to recognise my } \\
\text { feelings in the group }\end{array}$ & $\mathrm{EE}$ & .057 & .226 & .477 & .615 & .136 & .367 & .050 & .180 & .409 & .541 \\
\hline Eigenvalue & & 5.27 & & 2.69 & & 1.79 & & 1.28 & & 1.15 & \\
\hline $\begin{array}{l}\text { Proportion of explained common } \\
\text { variance (\%) }\end{array}$ & & 26.3 & & 13.4 & & 8.9 & & 6.4 & & 5.8 & \\
\hline Reliability estimate+ & & .902 & & .830 & & .813 & & .928 & & .793 & \\
\hline Cronbach's alpha & & .742 & & .702 & & .753 & & .845 & & .725 & \\
\hline Cronbach's alpha- standardised items & & .743 & & .702 & & .759 & & .845 & & .730 & \\
\hline
\end{tabular}

Absolute values greater than 0.4 shown in bold; High structure loading shown in grey.

EE- Emotional Expression; R- Relationships; GL- Group Learning; Cl- Cognitive Improvement; H- Overall perceived helpfulness; * - Inversely scored item; + (Mislevy \& Bock, 1990). 
Table 4 Correlation matrix for oblique rotation of 5 component analysis

\begin{tabular}{|c|c|c|c|c|c|}
\hline Component & $\begin{array}{l}\text { 1: Cognitive } \\
\text { improvement }\end{array}$ & $\begin{array}{l}\text { 2: Group } \\
\text { learning }\end{array}$ & 3: Relationships & $\begin{array}{l}\text { 4: Difficulties in } \\
\text { open expression }\end{array}$ & $\begin{array}{l}\text { 5: Sharing of emotions } \\
\text { and experiences }\end{array}$ \\
\hline 1: Cognitive Improvement & 1 & & & & \\
\hline 2: Group Learning & .230 & 1 & & & \\
\hline 3: Relationships & .159 & .271 & 1 & & \\
\hline 4: Difficulties in open expression & .266 & .118 & .147 & 1 & \\
\hline $\begin{array}{l}\text { 5: Sharing of emotions and } \\
\text { experiences }\end{array}$ & .059 & .199 & .208 & .095 & 1 \\
\hline
\end{tabular}

1) Altruism, 2) Instillation of hope, 4) Development of socializing abilities, 5) Catharsis, and 6) "Corrective recapitulation of the primary family group". The last factor supports reintegration and helps patients to accept insecure or maladaptive patterns of attachment which may have developed in infancy. Hence, it relates to attachment theory and can be particularly relevant to interventions utilising that theory. The items "I met new and positive people", "I built relationships of trust with others" and "I was helped by others" may also be representative of the dimension that Dierick and Lieater referred to as "relational climate" [28].

Table 5 Proposed 5 subscales and item reliability

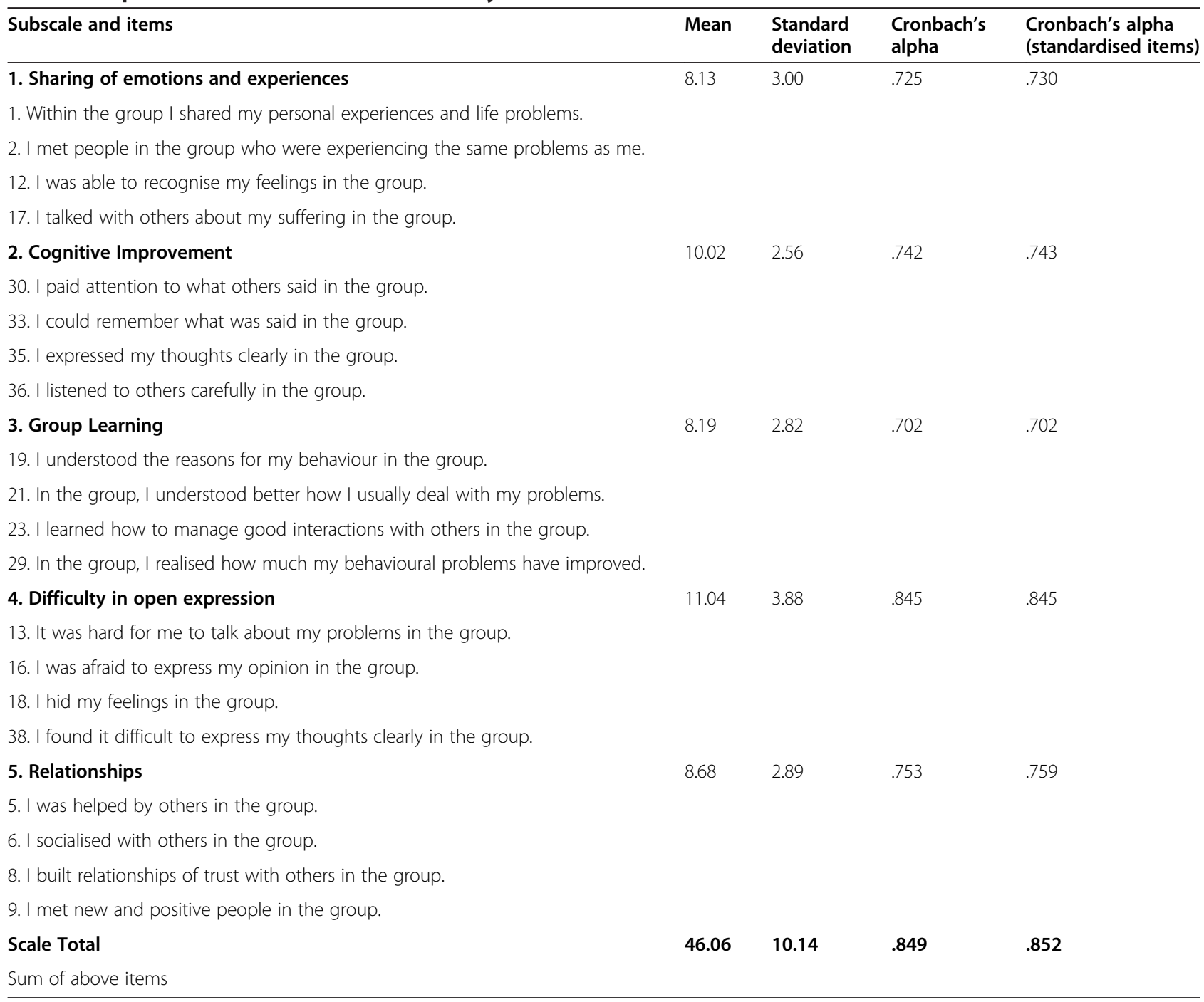




\section{Limitations}

The study has a number of limitations which should be taken into account. The limited sample size, from only one region of Italy means that results are not generalisable and will require further studies in different countries with larger samples. The measure was validated using a limited range of group treatments, each with differing approaches and levels of evidence to support their use in a clinical setting. It may therefore miss factors specific to a single modality of treatment. However, the application of the FE-GES across different modalities will enable comparisons to be made regarding the presence of common group factors.

As a consequence, the FE-GES should be crossvalidated in other countries and in other services with different group treatments.

Finally, patients with a psychiatric diagnosis were not involved in the focus groups to generate items for the questionnaire but were involved subsequently to modify the content so that it was clear and easy to understand.

As a consequence, the FE-GES should be crossvalidated in other countries and in other services with different group treatments.

\section{Conclusions}

The subscales of the FE-GES are conceptually similar to other studies of group therapeutic factors. Relational and Cognitive dimensions are particularly linked to those originally identified by Yalom and subsequently described by other authors as key therapeutic factors in group therapy $[6,7,22]$. These results suggest a fundamental connection between the emotional and cognitive components of group experiences. Through relational and emotive group experiences cognitive learning is further advanced [24-27,45]. The questionnaire has good face and content validity. Further studies with existing scales are now needed to confirm concurrent validity.

In summary, our preliminary validation indicates that the FE-GES appears a useful tool in the assessment of group treatment experiences of patients with severe mental illnesses. It is designed to detect distinct and typical factors of group experiences, and can be used to assess mediating processes and outcomes in research. Most importantly, it is very brief which is essential for a scale to be administered in routine care. The FE-GES can therefore be used in both research and in the evaluation and quality management of group treatments in routine care. It may aid not only clinical decision making and supervision, but also contribute to the further development of group therapy theory.

\section{Competing interests}

The authors declare that they have no competing interests.
Authors' contributions

$L G, B B, M R$ and SP wrote the proposal. RC, BB, LM, LB and MM participated in data collection. RC, BB and CC wrote the manuscript. CC analyzed the data. MR, LG and SP approved the proposal with some revisions and supervised the final paper. All authors read and approved the final manuscript.

\section{Acknowledgements}

The study has been supported by the University of Ferrara (University Funds for Scientific Research 2008-2009).

\section{Author details}

${ }^{1}$ Department of Behavior and Communication, Section of Psychiatry, University of Ferrara, Ferrara, Italy. ${ }^{2}$ Department of Mental Health and Drug Abuse, Ferrara Health Agency, Ferrara, Italy. ${ }^{3}$ Department of Mental Health and Drug Abuse, Bologna Health Agency, Bologna, Italy. ${ }^{4}$ Department of Neuroscience, Section of Psychiatry, University of Modena and Reggio Emilia, Modena, Italy. ${ }^{5}$ Unit for Social and Community Psychiatry, Queen Mary University of London, London, UK.

Received: 26 March 2013 Accepted: 25 September 2013

Published: 1 October 2013

\section{References}

1. Bion WR: Leaderless group project. Bull Menninger Clin 1946, 10:77-81.

2. Main T: The hospital as a therapeutic institution. Bull Menninger Clin 1946, 10:66-70.

3. Baker AA, Jones M, Merry J, Pomryn BA: A community method of psychotherapy. Br J Med Psychol 1953, 26:222-244

4. Foulkes SH, Anthony EJ: Group psychotherapy - the psychoanalytic approach. London: Karnac; 1957.

5. Bion WR, Bion WR, Experiences in Groups and Other Papers: London: tavistock publications and New York: routledge 1961. Reprinted Hove: Brunner-Routledge; 2001

6. Yalom ID: Inpatient group psychotherapy. New York: Basic Books; 1983.

7. Yalom ID, Leszcz M: The theory and practice of group psychotherapy. 4th edition. New York: Basic Books; 1995.

8. Granholm E, Holden J, Link PC, McQuaid JR, Jeste DV: Randomized controlled trial of cognitive behavioral social skills training for older consumers with schizophrenia: defeatist performance attitudes and functional outcome. Am J Geriatr Psychiatry 2012, 21(3):251-262.

9. Brenner HD: Integrated psychological therapy for schizophrenic patients. Gottingen, Germany: Hogrefe \& Huber; 1994.

10. Kopelowicz \& Lieberman: Behavioral treatment and rehabilitation in schizophrenia. Harv Rev Psychiatry 1995, 3:55-64.

11. McGurk SR, Twamley EW, Sitzer DI, McHugo GJ, Mueser KT: A meta-analysis of cognitive remediation in schizophrenia. Am J Psychiatry 2007, 164(12):1791-1802.

12. Eklund $M$, Hansson L: Relationships between characteristics of the ward atmosphere and treatment outcome in a psychiatric day-care unit based on occupational therapy. Acta Psychiatr Scand 1997, 95(4):329-335.

13. Röhricht F, Priebe S: Effect of body-oriented psychological therapy on negative symptoms in schizophrenia: a randomized controlled trial. Psychol Med 2006, 36(5):669-678.

14. Röhricht F, Papadopoulos N, Suzuki I, Priebe S: Ego-pathology, body experience, and body psychotherapy in chronic schizophrenia. Psychol Psychother 2009, 82(Pt 1):19-30.

15. Bechdolf A, Wagner M, Ruhrmann S, Harrigan S, Putzfeld V, Pukrop R, Brockhaus-Dumke A, Berning J, Janssen B, Decker P, Bottlender R, Maurer K, Möller HJ, Gaebel W, Häfner H, Maier W, Klosterkötter J: Preventing progression to first-episode psychosis in early initial prodromal states. Br J Psychiatry 2012, 200:22-29.

16. Fanning F, Foley S, Lawlor E, McWilliams S, Jackson D, Renwick L, Sutton M, Turner N, Kinsella A, Trimble T, O'Callaghan E: Group cognitive behavioural therapy for first episode psychosis: who's referred, who attends and who completes it? Early Interv Psychiatry 2012, 6(4):432-441.

17. Drury V, Birchwood M, Cochrane R: Cognitive therapy and recovery from acute psychosis: a controlled trial. Five-year follow-up. $\mathrm{Br} J$ Psychiatry 2000, 177:8-14.

18. Lewin K: A dynamic theory of personality. New York: McGraw-Hill; 1935.

19. Lewin K: Principles of topological psychology. New York: McGraw-Hill; 1936. 
20. Corsini R, Rosenberg B: Mechanisms of group psychotherapy: processes and dynamics. J Abnorm Soc Psychol 1955, 51:406-411.

21. Dickoff H, Lakin M: Patients' Views of group psychotherapy: retrospections and interpretations. Int I Group Psychother 1963, 13:61-73.

22. Bloch S, Crouch E: Therapeutic factors in group psychotherapy. Oxford: Oxford University Press; 1985.

23. Vlastelica M, Urlić I, Pavlović S: The assessment of the analytic group treatment efficiency according to Yalom's classification. Coll Antropol 2001, 25:227-237.

24. Leszcz M, Yalom ID, Norden M: The value of inpatient group psychotherapy: patients' perceptions. Int J Group Psychother 1985, 35(3):411-433.

25. Kahn EM, Webster PB, Storck MJ: Brief reports: curative factors in two types of inpatient psychotherapy groups. Int J Group Psychother 1986, 36:579-585.

26. Hastings-Vertino K, Getty C, Wooldridge P: Development of a tool to measure therapeutic factors in group process. Arch Psychiatr Nurs 1996, 10(4):221-228.

27. Lese KP, MacNair-Semands RR: The therapeutic factors inventory: development of a scale. Group 2000, 24:303-317.

28. Dierick P, Lietaer $\mathrm{G}$ : Client perception of therapeutic factors in group psychotherapy and growth groups: an empirically-based hierarchical model international journal of group psychotherapy. Int I Group Psychother 2008, 58(2):203-230.

29. Lorenzo-Seva U, Ferrando PJ, FACTOR: A computer program to fit the exploratory factor analysis model. Behav Res Methods 2006, 38(1):88-91.

30. Timmerman ME, Lorenzo-Seva U: Dimensionality assessment of ordered polytomous items with parallel analysis. Psychol Methods 2002, 16(2):209-220. 30.

31. Wilson P, Cooper C: Finding the magic number. The Psychol 2008, 21(10):866-867.

32. Stevens J: Applied multivariate statistics for the social sciences. 4th edition. Hillsdale, NJ: Erlbaum; 2002

33. Mislevy RJ, Bock RD: BILOG 3 item analysis and test scoring with binary logistic models. Mooresville: Scientific Software; 1990.

34. Berge JMF, Hofstee WKB: Coefficients alpha and reliabilities of unrotated and rotated components. Psychometrika 1999, 64:83-90.

35. Bentler M: Factor simplicity index and transformations. Psychometrika 1977, 59:567-579.

36. Lorenzo-Seva U: A factor simplicity index. Psychometrika 2003, 68:49-60

37. Streiner DL, Norman GR: Health measurement scales: a practical guide to their development and use. 4th edition. Oxford: Oxford University Press; 2008.

38. Muthén B, Kaplan D: A comparison of some methodologies for the factor analysis of non-normal likert variables. Brit J Math Stat Psychol 1985, 38(2):171-189.

39. Muthén B, Kaplan D: A comparison of some methodologies for the factor analysis of non-normal likert variables: a note on the size of the model. Brit J Math Stat Psychol 1992, 45:19-30.

40. Buja A, Eyuboglu N: Remarks on parallel analysis. Multivar Behav Res 1992, 27(4):509-540.

41. Flores PJ: Group psychotherapy and neuro-plasticity: an attachment theory perspective. Int J Group Psychother 2010, 60(4):546-570.

42. Hammond $\mathrm{ES}$, Marmarosh $\mathrm{CL}$ : The influence of individual attachment styles on group members' experience of therapist transitions. Int J Group Psychother 2011, 61(4):597-620.

43. Markin RD, Marmarosh C: Application of adult attachment theory to group member transference and the group therapy process. Psychotherapy (Chic) 2010, 47(1):111-121.

44. MacKenzie KR: Clinical applications of group developmental ideas. Group Dyn Theory Res Pract 1997, 1(4):275-278.

45. Lieberman MA, Yalom ID, Miles MB: Encounter groups: first facts. New York: Basic Books; 1973

doi:10.1186/1471-244X-13-242

Cite this article as: Caruso et al: Exploration of experiences in therapeutic groups for patients with severe mental illness: development of the Ferrara group experiences scale (FE- GES). BMC Psychiatry 2013 13:242.

\section{Submit your next manuscript to BioMed Central and take full advantage of:}

- Convenient online submission

- Thorough peer review

- No space constraints or color figure charges

- Immediate publication on acceptance

- Inclusion in PubMed, CAS, Scopus and Google Scholar

- Research which is freely available for redistribution 